\title{
Atmospheric Boundary Layer Turbulence in the Presence of Swell: Turbulent Kinetic Energy Budget, Monin-Obukhov Similarity Theory, and Inertial Dissipation Method
}

\author{
Zhongshui Zou, ${ }^{\text {a,b }}$ Shuiqing Li,, c,de Jian Huang,${ }^{\mathrm{f}}$ Peiliang Li, ${ }^{\mathrm{a}}$ Jinbao Song, ${ }^{\mathrm{a}}$ \\ JUN A. ZHANG, ${ }^{\mathrm{g}}$ AND ZHANHONG WAN ${ }^{\mathrm{a}}$ \\ ${ }^{a}$ Ocean College, Zhejiang University, Zhoushan, China \\ ${ }^{\mathrm{b}}$ Ocean Research Center of Zhou Shan, Zhejiang University, Zhoushan, China \\ ${ }^{\mathrm{c}}$ Key Laboratory of Ocean Circulation and Waves, Institute of Oceanology, Chinese Academy of Sciences, \\ Qingdao, China \\ ${ }^{\mathrm{d}}$ Laboratory for Ocean and Climate Dynamics, Qingdao National Laboratory for Marine Science and Technology, \\ Qingdao, China \\ ${ }^{\mathrm{e}}$ Center for Ocean Mega-Science, Chinese Academy of Sciences, Qingdao, China \\ ${ }^{\mathrm{f}}$ Guangzhou Institute of Tropical and Marine Meteorology, CMA, Guangdong, China \\ ${ }^{\mathrm{g}}$ Cooperative Institute for Marine and Atmospheric Studies, University of Miami, and Hurricane Research Division,
} NOAA/AOML, Miami, Florida

(Manuscript received 4 June 2019, in final form 29 February 2020)

\begin{abstract}
Turbulence over the mobile ocean surface has distinct properties compared to turbulence over land. Thus, findings that are based on the turbulent kinetic energy (TKE) budget and Monin-Obukhov similarity theory (MOST) over land may not be applicable to conditions over ocean partly because of the existence of a wave boundary layer (the lower part of atmospheric boundary layer including effects of surface waves; we used the term "WBL" in this article for convenience), where the total stress can be separated into turbulent stress and wave coherent stress. Here the turbulent stress is defined as the stress generated by wind shear and buoyancy, while the wave coherent stress accounts for the momentum transfer between ocean waves and atmosphere. In this study, applicability of the turbulent kinetic energy (TKE) budget and the inertial dissipation method (IDM) in the context of the MOST within the WBL are examined. It was found that turbulent transport terms in the TKE budget should not be neglected when calculating the total stress under swell conditions. This was confirmed by observations made on a fixed platform. The results also suggested that turbulent stress, rather than total stress, should be used when applying the MOST within the WBL. By combining the TKE budget and MOST, our study showed that the stress computed by the traditional IDM corresponds to the turbulent stress rather than the total stress. The swell wave coherent stress should be considered when applying the IDM to calculate the stress in the WBL.
\end{abstract}

\section{Introduction}

Turbulence mixing within the atmospheric boundary layer (ABL) provides a vital source of momentum and enables heat and water vapor to transfer across the airsea interface through fluxes. A better understanding of turbulent processes would improve the accuracy of oceanic and atmospheric models, and the development of long-term climate predictions.

The turbulent kinetic energy (TKE) budget and MoninObukhov similarity theory (MOST) are two widely tools for investigating turbulent processes within the ABL. Detailed knowledge of the TKE budget and MOST

Corresponding author: Jian Huang, hj@gd121.cn under different conditions is the key to determining the accuracy of turbulent closure schemes (such as the turbulent kinetic energy-mixing length model; Rutgersson et al. 2012; Wu et al. 2016) and the inertial dissipation method (IDM; Sjöblom and Smedman 2002; Hackerott et al. 2017). It is also useful for studying the influence of waves on the ABL (Hristov and Ruiz-Plancarte 2014).

The TKE budget has been comprehensively analyzed over land and ocean (e.g., Högström 1990; Sjöblom and Smedman 2003; Högström et al. 2009). A major difference in the $\mathrm{ABL}$ over ocean compared to land is the presence of ocean waves, which create their own wave boundary layer (WBL). The WBL is located in the lower part of the ABL and corresponds to a layer significantly influenced by oceans waves. Within the WBL, the total 
stress is the sum of turbulent stress and wave coherent stress. Note that the turbulent stress is generated by shear and buoyancy, while the wave coherent stress accounts for the momentum transfer between ocean waves and atmosphere. Since the wave coherent stress supports a significant part of total stress, the TKE budget over ocean become more complicated compared to that over the land (Högström et al. 2009).

Apart from allowing momentum transfer from air to water in atmospheric and oceanic models, MOST is also a convenient method for conversion of meteorological data according to different atmospheric heights and stability classes. The assumption of logarithmic scaling in the MOST is fundamental to calculating wind stress based on wind profile data. However, in a number of studies, it has been shown that upward momentum induced by swell waves (Grachev and Fairall 2001; García-Nava et al. 2012; Kahma et al. 2016) could generate a singular point in a wind profile (Högström et al. 2009; Smedman et al. 2009; Högström et al. 2013; Zou et al. 2018), which cannot be modeled within the framework of MOST. Babanin et al. (2018) also showed that a MOST-based logarithmic profile failed when the instruments were deployed within WBL or below the wave crests.

Based on the TKE budget and MOST, the IDM, similar to the eddy correlation method (ECM), is a basic method for computing air-sea fluxes, especially the measurements collected by moving ships and/or buoys, because the IDM is less sensitive to platform motion and flow distortion (Fairall et al. 1990). When the IDM is used to calculate the stress, it is usually assumed that the transport terms in the TKE budget can be neglected and the shear production term can be normalized to match with MOST. These assumptions have been verified over rigid land surface or wind-sea conditions (Sjöblom and Smedman 2002). However, under swell conditions, studies (Drennan et al. 1999; Grachev and Fairall 2001) have shown that the WBL can extend up to $10 \mathrm{~m}$ altitude, or even penetrate the atmospheric boundary layer, leading to a distinct behavior of the TKE budget (Högström et al. 2009). As a result, when observations were made within WBL, the IDM failed, for example, Drennan et al. (1999) found that swell can cause IDMderived fluxed to be much larger than that based on the ECM; Sjöblom and Smedman (2004) found that the IDM gave higher values than the ECM under swell conditions; whereas Pan et al. (2005) obtained the opposite result, that is, the ECM-derived stress was greater than that determined by the IDM.

The failure of the TKE budget, MOST, and IDM can pose many challenges to understanding the air-sea interaction, given that global wave climatologies have shown that swell waves are not rare but occur in most parts of the world's ocean basins (Hanley et al. 2010; Semedo et al. 2011). Thus, this study is focused on three questions regarding the turbulence processes in the presence of swell:

- How does the TKE budget behave under swell conditions?

- Is MOST valid within the swell WBL?

- Do IDM results agree with those of ECM, and if not, how can the discrepancy be interpreted?

This paper is organized as follows. The behavior of the TKE budget, MOST, and IDM within the WBL is explored in section 2 and the measurements used in this study are described in section 3. Section 4 shows the results, and section 5 provides the discussion and conclusion.

\section{The TKE budget, MOST, and IDM under swell conditions}

The TKE budget describes the generation and loss of TKE in the ABL. Under stationary and horizontally homogeneous conditions, it is given by (Kundu et al. 2012)

$$
-\overline{u w} \frac{\partial U}{\partial z}-\overline{v w} \frac{\partial V}{\partial z}+g \frac{\overline{w \theta_{v}}}{\bar{\theta}_{v}}-\frac{\partial \overline{w E}}{\partial z}-\frac{1}{\rho} \frac{\partial \overline{w p}}{\partial z}-\varepsilon=0,
$$

where $E=\left(u^{2}+v^{2}+w^{2}\right) / 2$ denotes the TKE; $U$ and $V$ represent the mean longitudinal and lateral wind speeds, respectively; $u, v$, and $w$ represent the wind fluctuation after removing the mean wind speed; $\theta_{v}$ is the virtual potential temperature fluctuation; $p$ is the pressure fluctuation; and the overbar is the time-averaging operator. The first two terms on the left side of Eq. (1) correspond to shear production of TKE, the third term is the production or loss of buoyancy, the fourth term is turbulent transport, the fifth term is pressure transport, and the final term is the molecular dissipation of the TKE.

Within the swell WBL, the fluctuation of a quantity can be further divided into swell coherent perturbations and turbulent perturbations, based on a triple decomposition (Buckley and Veron 2016). If it is assumed that there is no interaction between coherent perturbations and turbulence (Hristov and Ruiz-Plancarte 2014), the stress in Eq. (1), that is, $-\overline{u w}$ and $-\overline{v w}$, based on the ECM, becomes

$$
\tau=\tau_{\text {vis }}+\tau_{\text {turb }}+\tau_{\text {swell }}=\rho u_{*}^{2},
$$

where $\boldsymbol{\tau}_{\mathrm{vis}}$ is the viscous stress and can be neglected far from the water surface; $\tau_{\text {turb }}$ is the turbulent stress that is 
generated only by wind shear and buoyancy; and $\boldsymbol{\tau}_{\text {swell }}$ is swell wave coherent stress. When the waves travel in a different direction from the wind, the stresses should be considered as vectors:

$$
\begin{aligned}
\boldsymbol{\tau} & =-\overline{\rho u w \mathbf{i}}-\overline{\rho v w \mathbf{j}}, \\
\boldsymbol{\tau}_{\text {turb }} & =-\rho \overline{u^{\prime} w^{\prime} \mathbf{i}}-\rho \overline{v^{\prime} w^{\prime}} \mathbf{j}, \quad \text { and } \\
\boldsymbol{\tau}_{\text {swell }} & =-\rho \overline{\tilde{u} \tilde{w} \mathbf{i}}-\rho \overline{\tilde{v} \tilde{w} \mathbf{j}},
\end{aligned}
$$

where $\mathbf{i}$ and $\mathbf{j}$ represent the longitudinal ( $x$ axis) and lateral ( $y$ axis) unit vectors, respectively; and "'" and " " represent turbulent and swell coherent fluctuations, respectively. In the same way, the heat flux, TKE flux, pressure flux, and dissipation of TKE can also be expressed as

$$
\begin{aligned}
\overline{w \theta_{v}} & =\overline{w^{\prime} \theta_{v}^{\prime}}+\overline{\tilde{w} \tilde{\theta}}, \\
\overline{w E} & =\overline{w^{\prime} E^{\prime}}+\overline{\tilde{w} \tilde{E}}, \\
\overline{w p} & =\overline{w^{\prime} p^{\prime}}+\overline{\tilde{w} \tilde{p}}, \quad \text { and } \\
\varepsilon & =\varepsilon^{\prime}+\tilde{\varepsilon},
\end{aligned}
$$

where the first term on the right side of each function represents the turbulent part and the second term is the swell coherent part.

According to Hristov and Ruiz-Plancarte (2014), the kinetic energy balance for swell coherent perturbations is

$$
-\overline{\tilde{u} \tilde{w}} \frac{\partial U}{\partial z}-\overline{\tilde{v} \tilde{w}} \frac{\partial V}{\partial z}+g \frac{\overline{\tilde{w} \tilde{\theta}}}{\bar{\theta}_{v}}-\frac{\partial \overline{\tilde{w} \tilde{E}}}{\partial z}-\frac{1}{\rho} \frac{\partial \overline{\tilde{w} \tilde{p}}}{\partial z}-\tilde{\varepsilon}=0 .
$$

Usually, turbulent flow covers a wide range of frequencies of eddies, and larger eddies interact with themselves to yield small-scale eddies until they are sufficiently small to become heat. However, the swell coherent perturbations are confined to a frequency similar to that of surface waves, ranging from 0.05 to $\sim 10 \mathrm{~Hz}$. Because the swell coherent perturbations do not interact with the turbulence, there would be no viscous dissipation occurring in this range (Hristov and Ruiz-Plancarte 2014), therefore $\tilde{\varepsilon}$ can be neglected. Thus, Eq. (5) is reduced to

$$
\overline{\tilde{u}} \tilde{w} \frac{\partial U}{\partial z}+\overline{\tilde{v} \tilde{w}} \frac{\partial V}{\partial z}+\frac{\partial \overline{\tilde{w} \tilde{E}}}{\partial z}+\frac{1}{\rho} \frac{\partial \tilde{\tilde{w} \tilde{p}}}{\partial z}=0 ;
$$

here the swell coherent temperature flux is neglected because $\tilde{u}$ and $\tilde{\theta}$ are always in quadrature (Hristov and Ruiz-Plancarte 2014). At the water surface, the energy transfer across the air-sea interface occurs through work done by pressure $(\tilde{\tilde{w} \tilde{p}})$. In Eq. (6), this energy is extracted from the mean flow $\partial(U, V) / \partial z$ and leads to coherent momentum of swell waves.

By combining Eqs. (1), (3), (4), and (6), an equation identical to Eq. (5), but applicable to turbulence, is generated:

$$
-\overline{u^{\prime} w^{\prime}} \frac{\partial U}{\partial z}-\overline{v^{\prime} w^{\prime}} \frac{\partial V}{\partial z}+g \frac{\overline{w^{\prime} \theta_{v}^{\prime}}}{\bar{\theta}_{v}}-\frac{\partial \overline{w^{\prime} E^{\prime}}}{\partial z}-\frac{1}{\rho} \frac{\partial \overline{w^{\prime} p^{\prime}}}{\partial z}-\varepsilon^{\prime}=0 .
$$

When using the IDM to calculate the stress, it is usually assumed that the two transport terms in Eq. (1) are negligible, or in balance in terms of magnitude (Large and Pond 1982; Edson et al. 1991; Smith et al. 1992; Dupuis et al. 1997). Therefore, in combination with the MOST in which,

$$
\frac{\kappa z}{u_{*}} \frac{\partial U}{\partial z}=\varphi_{m}\left(\frac{z}{L}\right)
$$

where $\varphi_{m}$ is the nondimensional wind profile and $L=-u_{*}^{3} \theta_{v} / g \kappa \overline{w \theta_{v}}$ is the Obukhov length scale, Eq. (1) can be written as

$$
-\overline{u w} \frac{\partial U}{\partial z}-\overline{v w} \frac{\partial V}{\partial z}+\frac{g}{\overline{\theta_{v}}} \overline{w \theta_{v}}=\frac{u_{*}^{3}}{\kappa z}\left(\varphi_{m}-\frac{z}{L}\right)=\varepsilon^{\prime} .
$$

Here $\varepsilon=\varepsilon^{\prime}$ is used because $\tilde{\varepsilon}$ can be neglected. The form of $\varphi_{m}$ over the oceans is less studied (Högström et al. 2008), therefore the relationship obtained over land is usually taken (Edson et al. 1991). Dissipation rate $\varepsilon^{\prime}$ was determined from the inertial subrange of the velocity spectrum, assuming Kolmogorov similarity and applying Taylor's hypothesis (Sjöblom and Smedman 2004):

$$
\varepsilon^{\prime}=\frac{2 \pi f}{U}\left[\frac{f S(f)}{\alpha_{u}}\right]^{3 / 2}
$$

where $S(f)$ is the frequency velocity spectrum and $\alpha_{u}$ is the Kolmogorov constant for momentum ranging from 0.52 to 0.59 (Fairall et al. 1990; Iwata et al. 2005; Sahlée et al. 2008; Sørensen and Larsen 2010; Zhang 2010).

The assumption that the transport terms can be neglected has been questioned for a decade, due to the discrepancy in results between IDM and ECM (Sjöblom and Smedman 2004; Pan et al. 2005). An imbalance between the dissipation and production terms was also reported by Sjöblom and Smedman (2002), Sjöblom and Smedman (2003), and Högström et al. (2009) under swell conditions. If we assume the turbulent parts of the 
transport terms $\left[-\left(\partial \overline{w^{\prime} E^{\prime}} / \partial z\right)-(1 / \rho)\left(\partial \overline{w^{\prime} p^{\prime}} / \partial z\right)\right]$ can be neglected, Eq. (1) will take the form

$$
-\overline{u w} \frac{\partial U}{\partial z}-\overline{v w} \frac{\partial V}{\partial z}+g \frac{\overline{w^{\prime} \theta_{v}^{\prime}}}{\bar{\theta}_{v}}-\frac{\partial \overline{\tilde{w} \tilde{E}}}{\partial z}-\frac{1}{\rho} \frac{\partial \overline{\tilde{w} \tilde{p}}}{\partial z}=\varepsilon^{\prime} .
$$

Compared with traditional IDM [Eq. (9)], Eq. (11) shows that the swell parts of the transport terms $[-(\partial \tilde{w} \tilde{E} / \partial z)-(1 / \rho)(\partial \tilde{w} \tilde{p} / \partial z)]$ constitute the largest difference and lead to the imbalance between the dissipation and production terms. However, above the WBL where swell parts of the transport terms decay to zero, Eq. (11) will be reduced to Eq. (9).

Considering the complicated interaction between the pressure flux and mean wind [Eq. (6)], another convenient approach is to use Eq. (7) in the form of

$$
-\overline{u^{\prime} w^{\prime}} \frac{\partial U}{\partial z}-\overline{v^{\prime} w^{\prime}} \frac{\partial V}{\partial z}+g \frac{\overline{w^{\prime} \theta_{v}^{\prime}}}{\bar{\theta}_{v}}=\frac{u_{* \text { turb }}^{3}}{\kappa z}\left(\varphi_{m \text { turb }}-\frac{z}{L_{\text {turb }}}\right)=\varepsilon^{\prime},
$$

where

$$
\frac{\kappa z}{u_{* \text { turb }}} \frac{\partial U}{\partial z}=\varphi_{m \text { turb }}\left(\frac{z}{L_{\text {turb }}}\right) .
$$

Equation (13) represents the nondimensional wind profile and $L_{\text {turb }}=-u_{* \text { turb }}^{3} \theta_{v} / g \kappa \overline{w^{\prime} \theta_{v}^{\prime}}$ is the turbulent Obukhov length scale. Eq. (12) is very similar to Eq. (9), except for suggesting that the traditional IDM only provides turbulent stress. However, it should be noted that Eq. (12) is reduced to Eq. (9) above the WBL, because at this point the swell wave coherent stress becomes zero; thus, the turbulent stress is equal to the total stress.

\section{Data}

\section{a. Measurements}

Measurements were made on a hollow steel platform located in the South China Sea between 6 February and 8 May 2012. During the measurements, several eddy-correlation systems were used to observe turbulence variables for flux calculations, including threedimensional wind speeds, temperature, and water vapor concentrations at a sampling frequency of $20 \mathrm{~Hz}$. An acoustic wave and current (AWAC) sensor (Nortek, Rud, Norway) was moored on the seabed to record the directional wave data. It observed waves every $3 \mathrm{~h}$ and each wave measurement lasted $2048 \mathrm{~s}$, with a sampling frequency of $1 \mathrm{~Hz}$. In this study, wind turbulence measured at 8 and $20 \mathrm{~m}$ was used to calculate stress via the
ECM and IDM; 30-min-averaged wind speeds at 8, 20, and $28 \mathrm{~m}$ were used to find the wind gradient to calculate the nondimensional wind profile.

The location of the measurements, together with an overview of the observational data, are shown in Fig. 1. The data observed at $8-\mathrm{m}$ altitude were used to plot a wind rose (Fig. 1a). The figure shows that winds were not strong, being mostly in the $2-8 \mathrm{~m} \mathrm{~s}^{-1}$ range and originated mostly from the open sea between $70^{\circ}$ and $130^{\circ}$. The distribution of significant waves from different directions is shown in Fig. 1b, and a wave age frequency histogram is shown in Fig. 1c. Here, the wave age was defined as $c_{p} / U_{8} \cos \left(\alpha_{\text {turb }}-\alpha_{\text {wave }}\right)$, where $\alpha_{\text {turb }}$ and $\alpha_{\text {wave }}$ represent the angles of the turbulent stress and wave stress that are deviated from the wind direction, respectively. It can be seen that swell waves (wave age greater than 1.2 or negative) were generally dominant and they were transported steadily from the open sea.

\section{b. Data processing procedures}

To evaluate the influence of swell waves on turbulent properties, data points during the swell period should be selected. Several studies (Rieder and Smith 1998; Soloviev and Kudryavtsev 2010; Högström et al. 2015) have shown that swell coherent perturbations could induce a pronounced peak in the wind velocity power spectrum. This peak is centered at the frequency of the dominant wave and can be a useful feature to check if the stress is affected by swell. Our data (Fig. 2) shows that measurements obtained at a height of $8 \mathrm{~m}$ were within the swell WBL, because they were always affected by swell. However, above $20 \mathrm{~m}$, the peak swell was not obvious, and therefore only data with a clear swell peak at a height of $8 \mathrm{~m}$ were included in the final analysis.

Before analyzing the influence of swell waves on turbulence properties, the selected turbulent data were subjected to quality control procedures (Zou et al. 2017), to guarantee the accuracy of the results. Additionally, the influence of mesoscale processes on turbulence was manually checked using an ogive graph; regarding dissipation, wind spectra that did not have a clear $f^{-5 / 3}$ relationship were rejected. Then the stress $u_{* \text { IDM }}^{2}$ can be computed from IDM by inputting height $z$ and buoyancy flux into Eq. (9) or Eq. (12) and the inertial subrange of $S(f)$, wind speed $U$ into Eq. (10). Here the inertial subrange in $S(f)$ was found by best fitting it to the $f^{-5 / 3}$ relationship. For turbulent stress and swell wave coherent stress, they were derived from the cospectra between the downwind $u$, crosswind $v$, and the vertical $w$, following Zou et al. (2019) after the total stress $u_{*}^{2}$ computed from ECM [Eq. (3a)] (the method used to derive turbulent stress and swell wave coherent stress is detailed described in the appendix). During this 

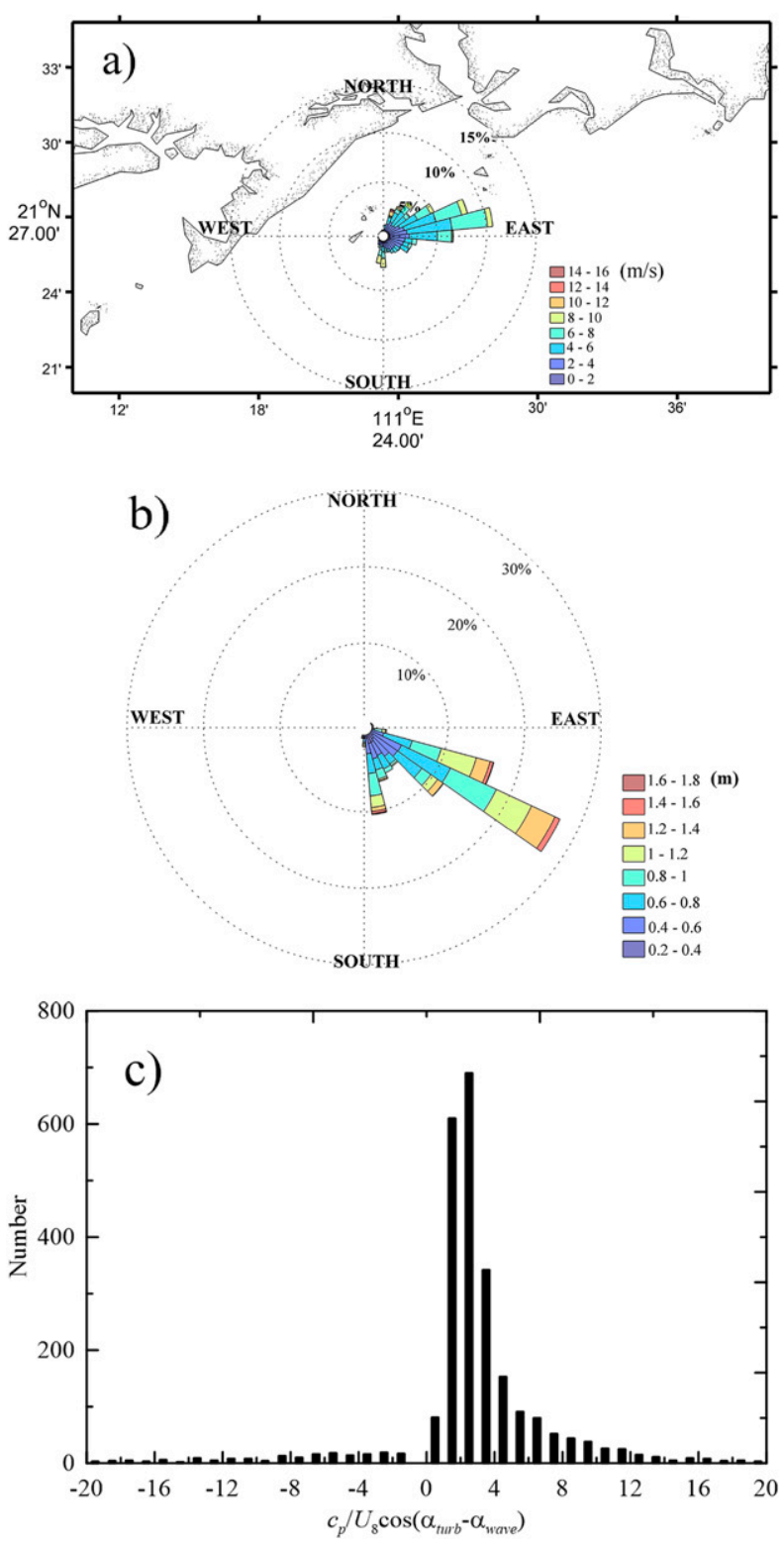

FIG. 1. (a)-(c) Measuring locations and overview of the observed data. The wind roses in (a) and (b) show the distribution of winds and significant waves, all measured at 8-m height. The data were averaged over $30 \mathrm{~min}$ to obtain the mean values. The convention is the meteorological one, where the direction is given "from" which the wind and waves come. The frequency histogram of wave age is given in (c).

procedure, the swell information, including spectrum and direction, are needed. These variables were derived from directional wave spectrum using the Wave Identification and Tracking System (Hanson and Jensen 2004).

\section{Comparison with observations}

Section 2 shows that the swell wave-related transport terms in Eq. (11) constituted the major difference between
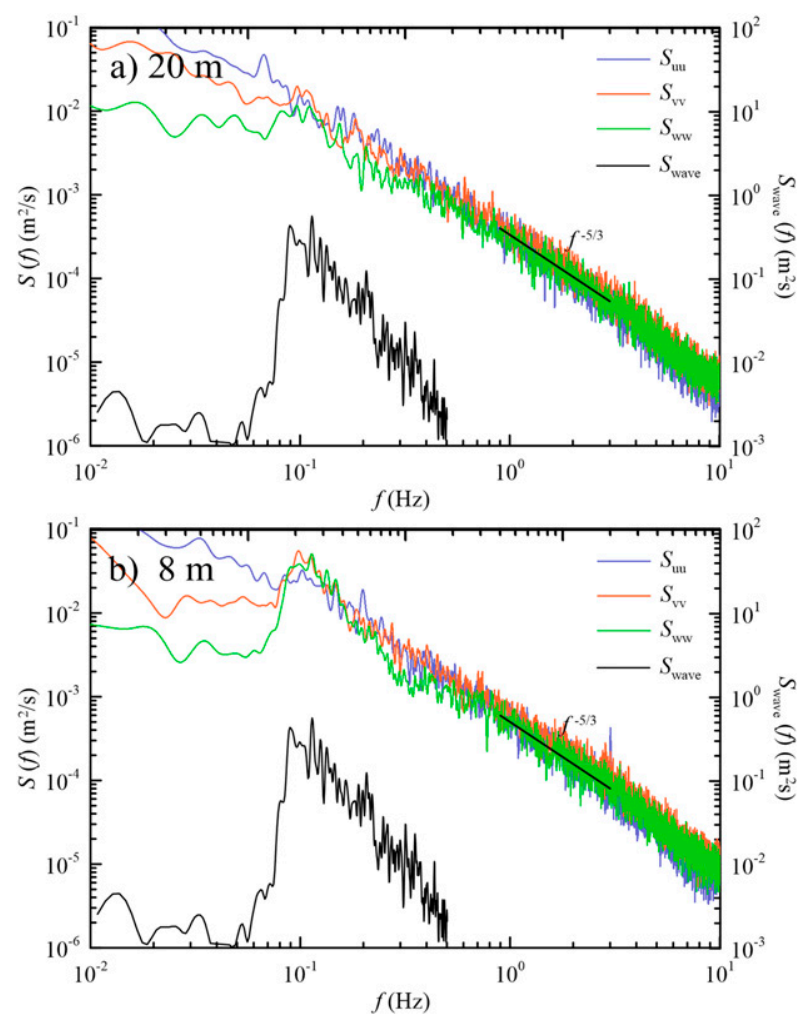

FIG. 2. A frequency spectra example of the wind speed fluctuation at (a) 20 and (b) $8 \mathrm{~m}$ above the sea surface, together with sea surface displacement. The blue $\left(S_{u u}\right)$, orange $\left(S_{v v}\right)$, and green $\left(S_{w w}\right)$ lines represent the spectra of longitudinal, lateral, and vertical wind fluctuation, respectively. The black lines $\left(S_{\text {wave }}\right)$ are wave spectra.

the TKE budget terms within and above the WBL. Equation (12) suggests that the stress computed from the IDM corresponds to the turbulent stress. During this procedure, the turbulent parts of the transport terms are neglected, and the IDM relied on a nondimensional wind profile $\varphi_{m \text { turb }}$ and atmospheric stability $z / L_{\text {turb }}$, calculated by the turbulent stress rather than total stress. This led to the questions raised in the introduction section being phrased in another way:

1) Do the swell parts of the transport terms truly play a significant role in TKE budget (the first question in the introduction)?

2) Can the nondimensional wind profile over land or a wind sea depict the behavior of $\varphi_{m \text { turb }}$ (the second question in the introduction)?

3) Does the momentum derived from the IDM [Eq. (12)] truly represent the turbulent stress alone (the third question in the introduction)?

These questions will be addressed in this section.

Many studies (e.g., Grachev et al. 2003; Högström et al. 2015; Kahma et al. 2016) have shown that swell 
waves can both generate upward momentum and absorb energy from winds. According to Eq. (3), the magnitude of the total stress can be expressed as

$|\boldsymbol{\tau}|=\sqrt{\left|\boldsymbol{\tau}_{\text {turb }}\right|^{2}+\left|\boldsymbol{\tau}_{\text {swell }}\right|^{2}+2\left|\boldsymbol{\tau}_{\text {turb }}\right|\left|\boldsymbol{\tau}_{\text {swell }}\right| \cos \left(\alpha_{\text {turb }}-\alpha_{\text {swell }}\right)}$.

This equation shows that when $\cos \left(\alpha_{\text {turb }}-\alpha_{\text {swell }}\right)<$ $-0.5\left|\boldsymbol{\tau}_{\text {swell }}\right| /\left|\boldsymbol{\tau}_{\text {turb }}\right|$, swell exerts upward momentum such that the total stress is lower than the turbulent stress. For $\cos \left(\alpha_{\text {turb }}-\alpha_{\text {swell }}\right)>-0.5\left|\boldsymbol{\tau}_{\text {swell }}\right| /\left|\boldsymbol{\tau}_{\text {turb }}\right|$, the total stress becomes larger. To distinguish the above situations, the data were separated into two cases: case 1 corresponds to the total stress being lower than the turbulent stress, while case 2 corresponds to the total stress being greater than the turbulent stress.

\section{a. TKE budget}

Figure 3 shows the normalized production $\varphi_{p}=$ $\varphi_{m}-(z / L)$ and dissipation $\varphi_{\varepsilon}=-\left(\kappa z / u_{*}^{3}\right) \varepsilon$ within and above the swell WBL, as a function of stability. Here, we used a Kolmogorov constant of 0.58 to calculate the dissipation rate by inputting $S(f)$ in the inertial subrange and wind speed $U$ into Eq. (10). The magnitudes of the production and dissipation at 8 and $20 \mathrm{~m}$ seem similar, both increasing with stability. However, a careful inspection shows that by separating the data into these two cases, the magnitudes of the production and dissipation terms in case 1 were higher than those in case 2 at $8-\mathrm{m}$ altitude. In contrast, the difference between the two cases at $20 \mathrm{~m}$ was not significant. One may query that the case 1 at $20 \mathrm{~m}$ has slightly higher values than case 2 for $z / L>0.2$. However, it should be noted that case 2 has a small number of samples at this stability range thus the average values of case 2 should be used with caution.

To check if the dissipation term can truly be in balance with respect to the production term, Fig. 4 shows the normalized transport terms $\varphi_{t}=-\left(\kappa z / u_{*}^{3}\right)[(\partial \overline{w E} / \partial z)+(1 / \rho)(\partial \overline{w p} / \partial z)]$ as a function of stability. Here the transport terms were determined as a residual after the other terms in Eq. (1) were evaluated directly from observations. The influence of swell waves at $20 \mathrm{~m}$ above the sea surface was almost zero; thus, the transport terms at $20 \mathrm{~m}$ (Fig. 4a) were reduced to the turbulent parts of the transport terms. There is a considerable scatter in the figure, which became more significant as the stability conditions is transitioned from unstable to stable.

A comparison of the bin-averaged values of our data with the results of several earlier studies is shown in Fig. 5. Yelland and Taylor (1996) and Hackerott et al. (2017) showed the dependence of the transport terms on atmospheric stability, but the trends were different under unstable conditions. The results of Sjöblom and Smedman (2003)
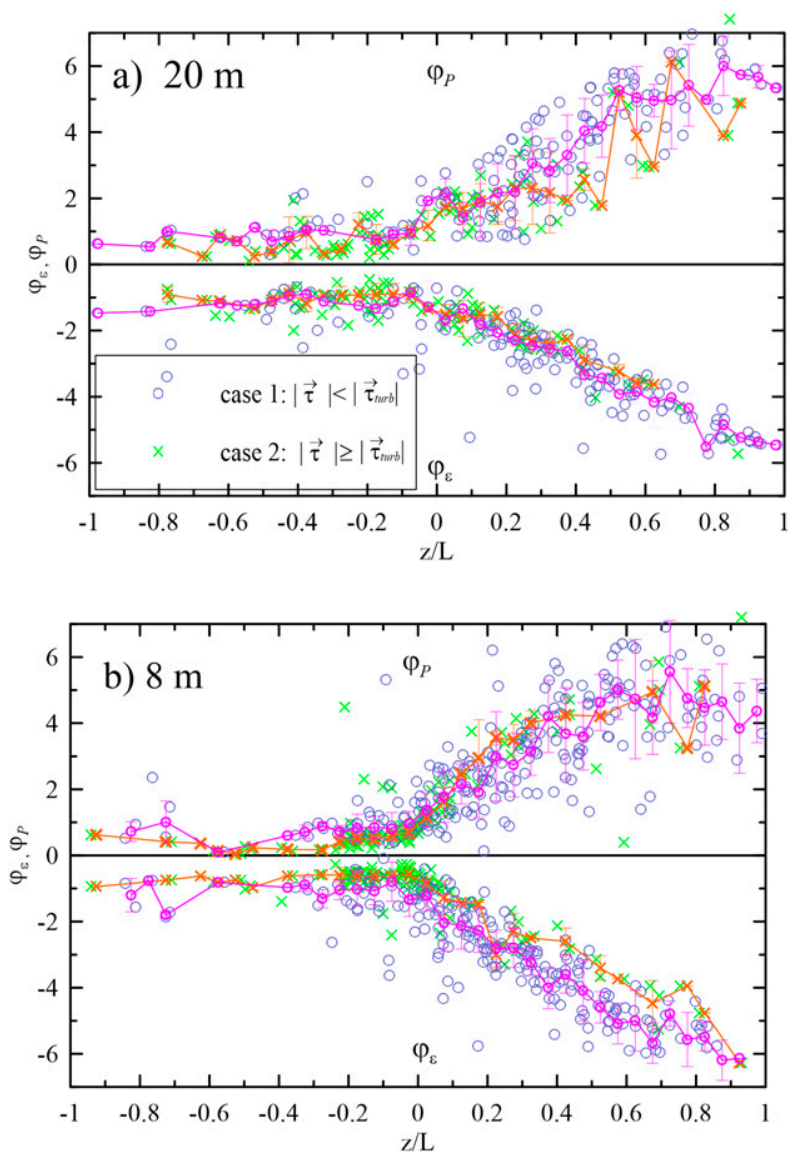

FIG. 3. Normalized production and dissipation as a function of stability at (a) 20 and (b) $8 \mathrm{~m}$. The blue circles and the green crosses show all the data of cases 1 and 2, and the magenta circles and orange crosses show their mean values, respectively.

also are differed by height, with a strong dependence on stability at $10 \mathrm{~m}$ where there was a significant influence from swell waves, but the results were almost constant at 18- and 26-m altitudes. In contrast, no imbalance between production and dissipation terms over the sea surface was found by Edson and Fairall (1998) (not shown here).

In our results, the dependence of the transport terms on atmospheric stability was not clear and they fluctuated around the zero line. The imbalance between the dissipation and production terms also depends on the choice of the Kolmogorov constant. Kolmogorov constants of 0.54 and 0.62 were assessed in terms of their influence on the transport terms (Fig. 5). It was found that varying the Kolmogorov constant only weakly affected the magnitudes of the transport terms but did not change the overall trend of variation of the transport term as the function of stability.

Figure 6 shows the changes in cases 1 and 2 as a function of stability. The two cases were similar at $20 \mathrm{~m}$, 

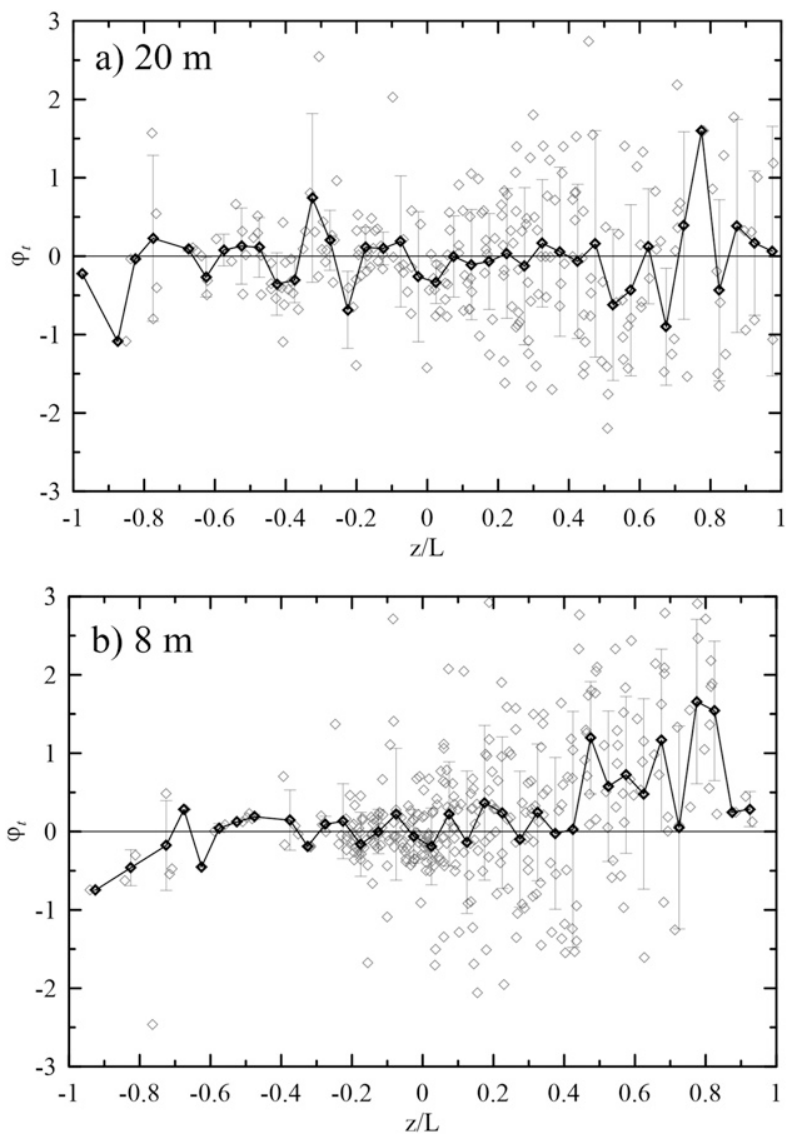

FIG. 4. Normalized transport terms as a function of stability at (a) 20 and (b) $8 \mathrm{~m}$. The black diamonds denote the bin-averaged mean values, together with the standard deviation.

but the 8 -m case 1 was almost positive, while case 2 was negative, indicating a significant influence of swell waves on the transport terms.

We also plotted the transport terms as a function of wave age in Fig. 7, to assess the influence of swell waves on the transport terms. Figure 4 shows that the transport terms became widely scattered under stable conditions. To eliminate the influence of stability on the transport terms, only stability parameters ranging from -0.2 to 0.4 were considered in Fig. 7. The transport terms at $8 \mathrm{~m}$ slowly increased with wave age. When the wind was blowing against the swell wave (case 1), the production term exceeded the dissipation term; and when the wind was blowing along the swell wave (case 2), the dissipation was larger than production. However, this relationship was not found at $20 \mathrm{~m}$.

\section{b. MOST}

In the $\mathrm{ABL}$, in which turbulence is generated through shear and buoyancy, the MOST uses one parameter with the dimension of length to describe the ratio of the

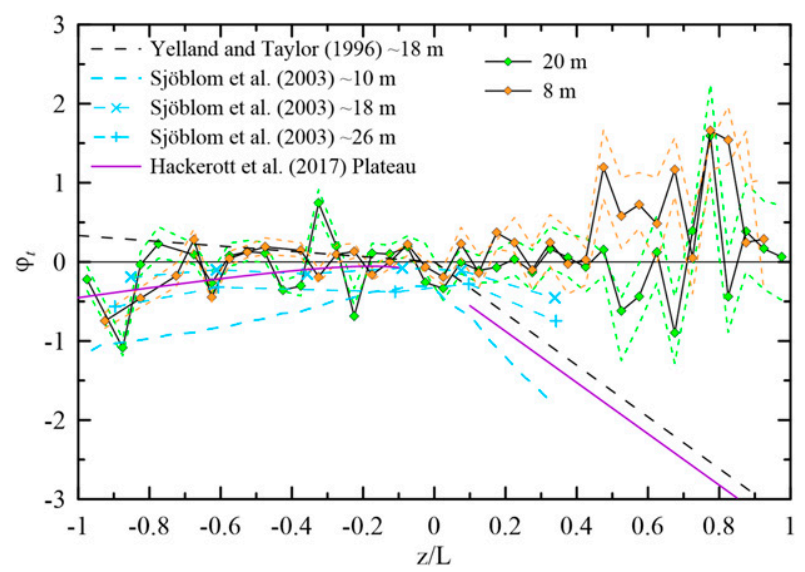

FIG. 5. Comparison of our transport term results with earlier studies. The diamonds are bin-averaged mean values of the data points in Fig. 4, and the orange and green dashed lines around the diamonds show the dependence of transport term on Kolmogorov constants. Here the upper and lower dashed lines are computed by using Kolmogorov constants of 0.54 and 0.62 , respectively.

buoyancy and shearing effects and expresses the nondimensional wind profile as a function of stability parameter. According to the definition of MOST, it can only depict the turbulent momentum transfer occurring within the ABL. However, close to the ocean surface, the momentum induced by waves gradually dominates and replaces the turbulent stress. At this time, by normalizing the shear production using $\kappa z / u_{*}^{3}$ to obtain a nondimensional wind profile, a wave age-dependent $\varphi_{m}$ will be obtained (Sjöblom and Smedman 2003), because $u_{*}$ contains both turbulent and wave related effects. The swell wave coherent stress within the total stress can also affect the stability parameter by reducing or enlarging the total stress, because the total stress could play a decisive role in the variation in $z / L$. This implies that $z / L$ may not represent the true atmospheric stability in the WBL.

Figure 8 shows the changes in the nondimensional wind profile as a function of stability [Eq. (8)], together with the results of two earlier studies (Högström 1988; Zou et al. 2017). It should be noted that Zou et al. (2017) used data obtained from the same platform as the data used in the present study, but only made observations at $20 \mathrm{~m}$ above the sea surface, which was free from the effect of swell, while the data in Högström (1988) were obtained over a land surface. Figure 8 shows that the scatter is relatively large in the nondimensional wind profile, especially under stable conditions due to selfcorrelation (Klipp and Mahrt 2004; Baas et al. 2006). However, if we focus on the stability parameter ranging from -0.3 to 0.1 , it can be found that the averaged nondimensional wind profile derived from $u_{*}$ (Fig. 8a) is 

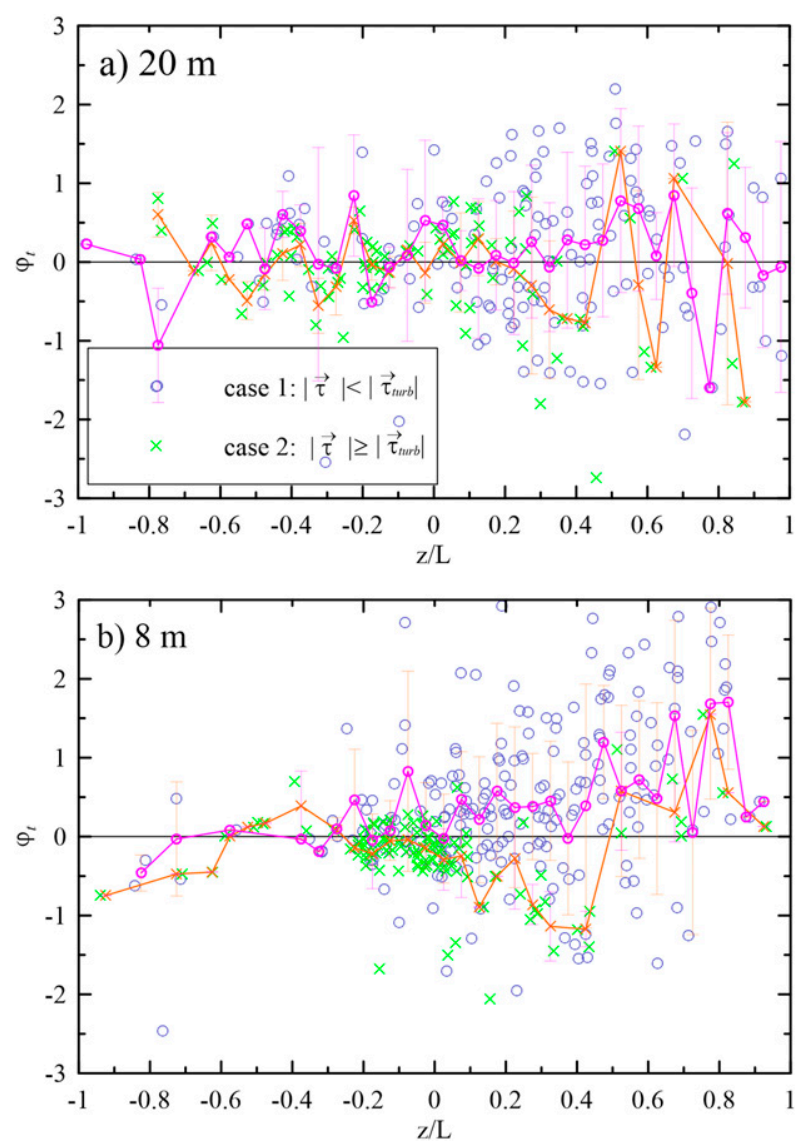

FIG. 6. Normalized transport terms as a function of stability at (a) 20 and (b) $8 \mathrm{~m}$, obtained by separating the data into two cases ( 1 and 2 ) based on the relationship between total stress and turbulent stress. The blue circles and the green crosses show all the data of cases 1 and 2, and the magenta circles and orange crosses show their mean values, respectively.

different from that reported in earlier studies. The mean values for case 1 are slightly larger than those in Högström (1988) and Zou et al. (2017). On the other hand, the mean values for case 2 are smaller.

The nondimensional wind profile derived from the turbulent stress [Eq. (13)] is shown in Fig. 8b. It can be seen that the results from the two cases were similar, both being in good agreement with earlier studies, especially for $-0.2<z / L<0.1$. This suggests that the different behavior of $\varphi_{m}$ between cases 1 and 2 at $8 \mathrm{~m}$ was induced by swell waves; the turbulent stress, rather than the total stress, should be used in MOST.

\section{c. Momentum flux derived from the IDM}

The accuracy of the IDM relies heavily on the choice of the inertial subrange, Kolmogorov constant, and the parameterization of $\varphi_{m}$ (Yelland and Taylor 1996). Figure 2 shows that a clear inertial subrange was typically observed at high frequencies. In this study, the
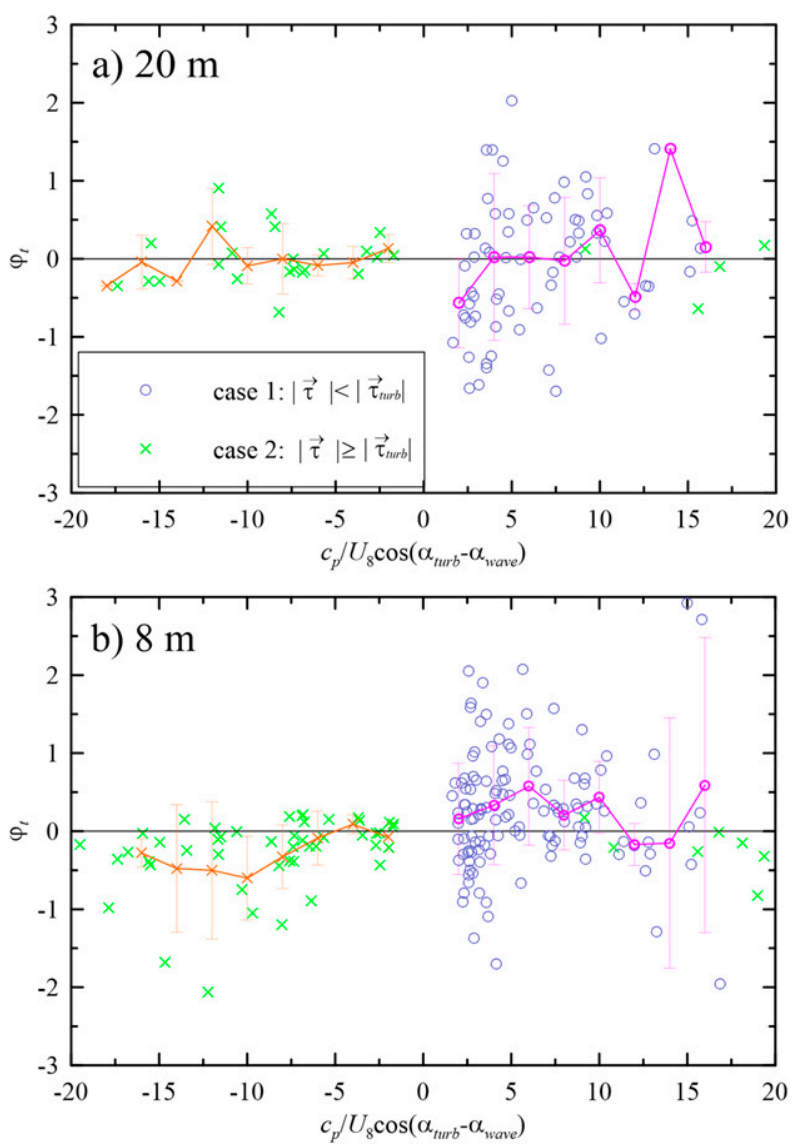

FIG. 7. Normalized transport terms as a function of wave age at (a) 20 and (b) $8 \mathrm{~m}$. The blue circles and the green crosses show all the data of cases 1 and 2, and the magenta circles and orange crosses show their mean values, respectively.

inertial subrange was selected by fitting a slope of $-5 / 3$ to the velocity spectrum.

Using the same platform, but only with data from $20 \mathrm{~m}$ above the sea surface, Zou et al. (2017) demonstrated that the platform data agreed well with Högström (1988) (Fig. 8); thus, the $\varphi_{m}$ value from Högström (1988) was used for our analysis. For the Kolmogorov constant, a value of 0.58 was used because the IDM fitted the ECM well for the data obtained at $20 \mathrm{~m}$. Assuming that $\varphi_{m}$ and the Kolmogorov constant are independent of height, the stress at $8 \mathrm{~m}$ above the sea surface can therefore be derived in the same way as at $20 \mathrm{~m}$.

Figure 9 gives the friction velocity $u_{*}$ derived from the ECM compared to that derived from the IDM using Eq. (9). To produce the data in Fig. 9, the buoyancy flux from the ECM was used to calculate the stability parameter $z / L$. This allowed a direct comparison between the IDM and ECM by eliminating any uncertainties from the buoyancy flux. The data in Fig. 9a indicate that the IDM-derived results were in good agreement with 

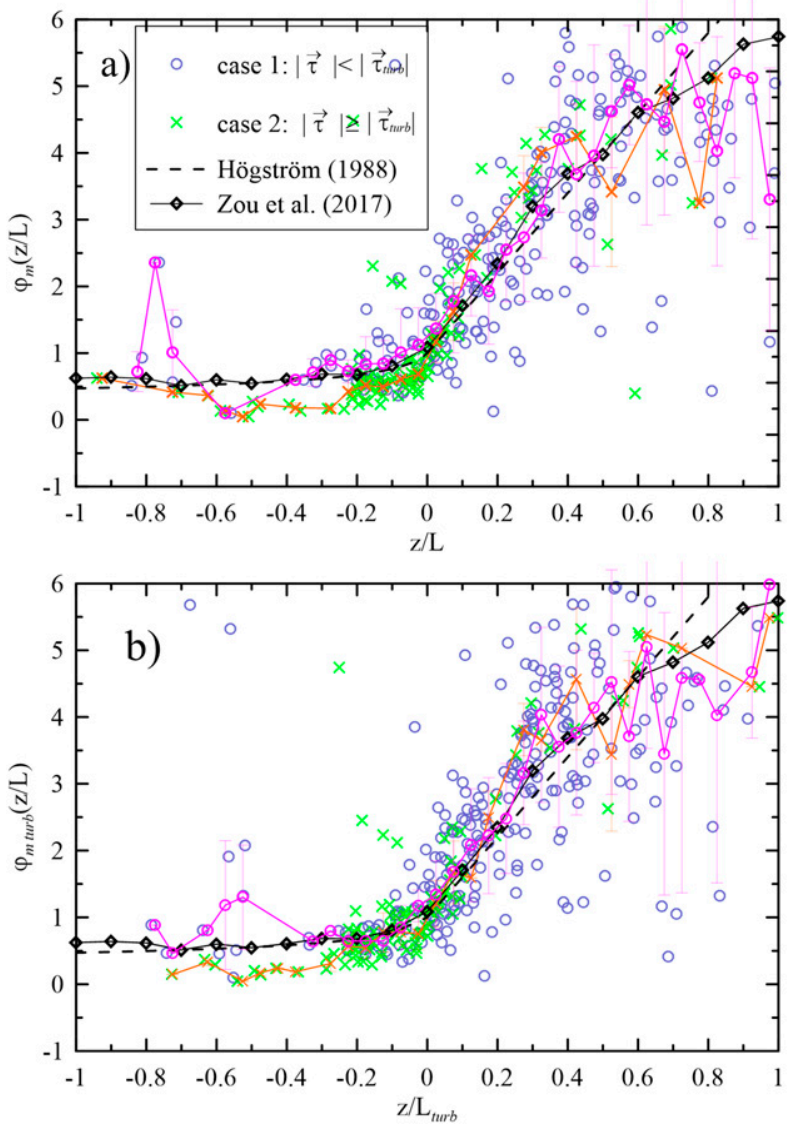

FIG. 8. Changes in the nondimensional wind profile with atmospheric stability, calculated by (a) total stress and (b) turbulent stress. The blue circles and the green crosses show all the data of cases 1 and 2, and the magenta circles and orange crosses show their mean values, respectively.

the ECM results. However, at $8 \mathrm{~m}$ above the sea surface (Fig. 9b), the IDM generated a larger value than the ECM for case 1, in a same manner as reported by Sjöblom and Smedman (2004). For case 2, when swell waves absorbed momentum from the ABL, our results were similar to those of Pan et al. (2005), who reported a smaller value of momentum flux than that computed by the ECM. The influence of swell waves on the stress at $8 \mathrm{~m}$ was obvious compared to the situation at $20 \mathrm{~m}$. Thus, it is reasonable to link the phenomena shown in Fig. 9b) with swell.

Sjöblom and Smedman (2004) used a wave agedependent Kolmogorov constant to eliminate the discrepancy between the IDM and ECM. In contrast, Pan et al. (2005) introduced a swell term in the TKE budget by considering swell-induced wind. Our analysis in section 2 suggested that the transport terms, especially the swell-coherent part, should not be neglected within the WBL, which was in agreement with Sjöblom and Smedman (2002) and Högström et al. (2009).
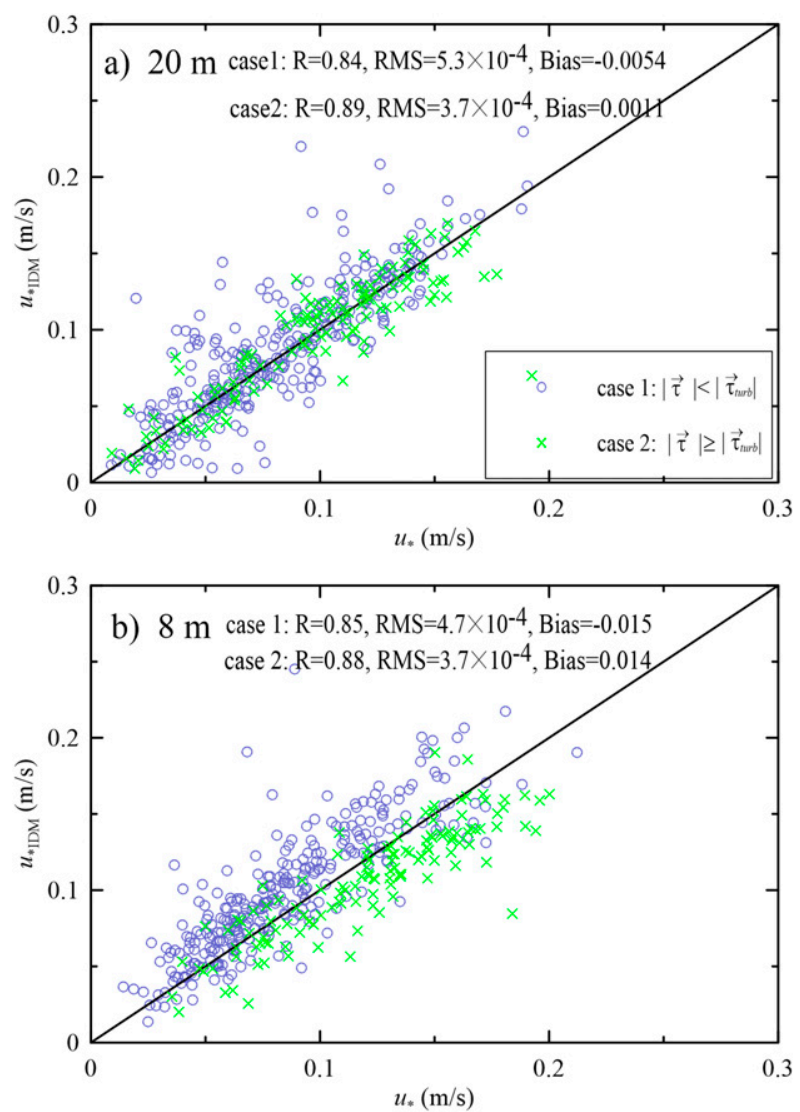

FIG. 9. Comparison of friction velocity between the ECM $\left(u_{*}\right)$ and the IDM $\left(u_{* \text { IDM }}\right)$. Measurements at (a) 20 - and (b) 8-m height above sea surface. The blue circles and green crosses correspond to cases 1 and 2, respectively.

If the turbulent parts of the transport terms can be neglected, Eq. (12) suggests that the IDM only gave the turbulent stress based on a turbulence-computed nondimensional wind profile and atmospheric stability. Our result shows that the turbulent parts of the transport terms did not show a clear dependence on stability or wave age. Instead, they behaved more like "random error," indicating those terms can be truly neglected. Figure $8 \mathrm{~b}$ also shows that the nondimensional wind profile derived from $u_{* \text { turb }}$ coincided with the result obtained from land or nonswell waves; thus, the nondimensional wind profile found over land or a wind-sea could depict the behavior of $\varphi_{m \text { turb }}$. Next, we investigated if the stress computed from IDM corresponds to turbulent stress.

The friction velocity determined from Eq. (12) was plotted against the total stress and turbulent stress as in Fig. 10. The correlation coefficient and root-meansquare (RMS) and bias are also given for comparison. The figure shows that the IDM derived stress was more coincident with the turbulent stress than with total stress, with correlation coefficients of 0.87 and 0.82 , respectively. 


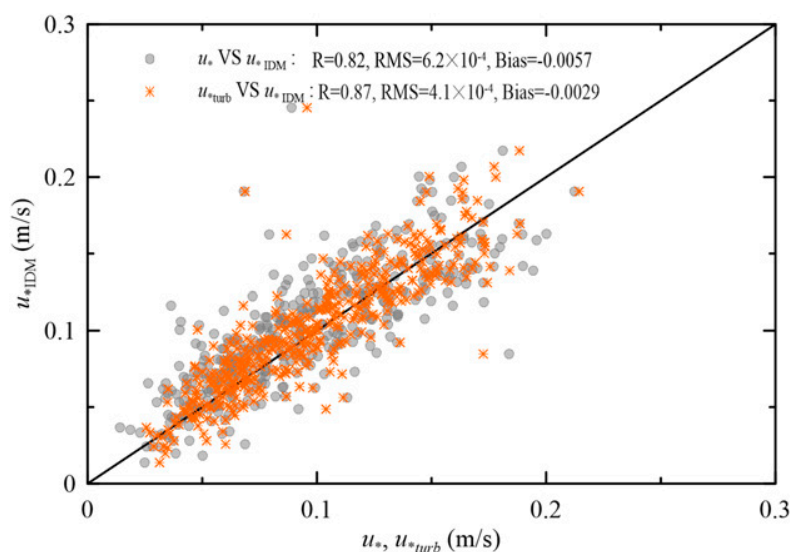

FIG. 10. Friction velocity determined using the traditional IDM ( $u_{* \text { IDM }}$ ) plotted against turbulent stress $u_{* \text { turb }}$ and total stress $u_{*}$.

Additionally, the bias in the IDM stress compared to the turbulent stress was smaller than compared to the total stress. These features confirm that the traditional IDM only gives the turbulent wind stress. This offers an explanation for the result in Fig. 9b: when swell waves exert upward momentum (case 1), the total stress will be less than the turbulent stress. Thus, the IDM gives a higher value than the ECM; whereas the swell waves absorb momentum from the ABL (case 2), the momentum derived from the IDM will be less than the total stress.

After the turbulent stress was obtained using the traditional IDM, the total stress could be calculated according to Eq. (2), in which the swell wave coherent stress is derived according to the appendix. The results are shown in Fig. 11. By considering the effect of swell on the IDM ( $\left.u_{* \text { IDMtot }}\right)$, good quantitative agreement with $u_{*}$ was found. This improved the correlation coefficient from 0.82 to 0.87 and reduced the bias from -0.0057 to -0.0026 .

\section{Discussion and conclusions}

The mobility of the ocean surface could make the turbulent properties within the ABL over the ocean largely different from the turbulence found over land. In this study, the influence of swell waves on the TKE budget and MOST within the swell WBL was analyzed. It was found that the swell wave component of the transport terms was the largest difference within the WBL. This was further confirmed by observational data collected at two levels on a fixed platform in the South China Sea. The results showed that the swell associated transport terms in the TKE budget were dependent on the wave age at $8 \mathrm{~m}$ above the surface, but not at 20-m altitude.

The use of a logarithmic wind profile based on MOST is a common approach to determine wind stress. Our study

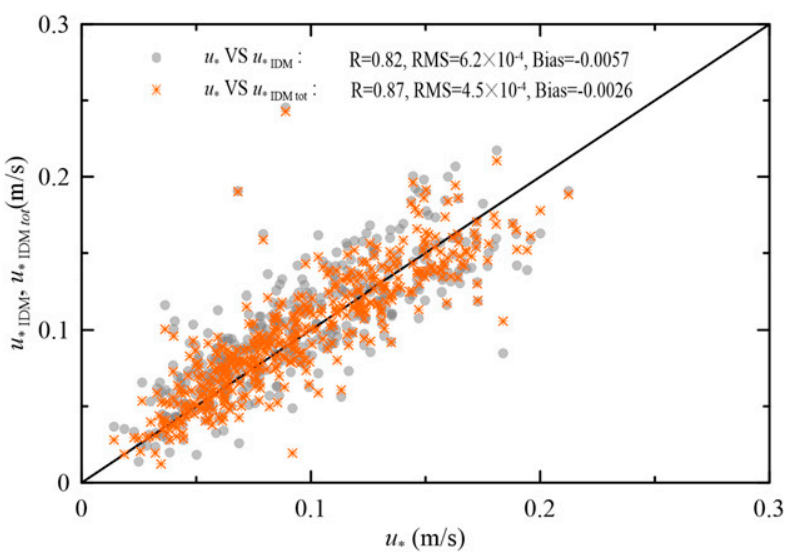

FIG. 11. Comparison of the total friction velocity determined from ECM $\left(u_{*}\right)$ and using the IDM $\left(u_{* \text { IDMtot }}\right)$. The shaded circles represent the traditional IDM $\left(u_{* \text { IDM }}\right)$ compared to total stress $\left(u_{*}\right)$.

shows that within the WBL, MOST should only use turbulent stress, that is, $K_{m}=\kappa u_{* \operatorname{turb}} z / \varphi_{m \text { turb }}$, instead of the total stress. This may be the reason why observations made very close to the water surface appear discrepancies between the wind stress derived from a wind profile method and the ECM (Babanin et al. 2018; Voermans et al. 2019).

The accurate parameterization of each term in the TKE budget and MOST played a decisive role in the IDM. Sjöblom and Smedman (2004) and Pan et al. (2005) reported controversial results when comparing the IDM and ECM. The data used in Sjöblom and Smedman (2004) were collected on a small island, with the wind and swell waves running in the same direction, thus corresponding to our case 1 . Meanwhile, the data in Pan et al. (2005) corresponded to our case 2, as the wind was blowing from the coast, with swell propagating from the open sea. Considering the influence of swell on the TKE budget and MOST, our analysis suggested that the stress computed by the IDM corresponds to turbulent stress; the discrepancy between the results of Sjöblom and Smedman (2004) and Pan et al. (2005) can be explained by the difference in swell-induced stress in these two studies (section 4c). Our study also suggested that when using IDM to calculate total stress in the WBL, the swell wave coherent stress should be included. Our result showed improved correlation and reduced bias comparing the stress based on this method and the traditional IDM to the ECM derived stress in the WBL.

In the end, a question arises as to the height of the WBL, that is, the height where the swell wave coherent stress becomes negligible. Experiments by Högström et al. (2009) showed that wave coherent stress decays with height in a relationship of $\exp (-A k z)$, where $A \approx 2$. While Wu et al. (2018) showed that $A$ ranged from 5 to 25 , 

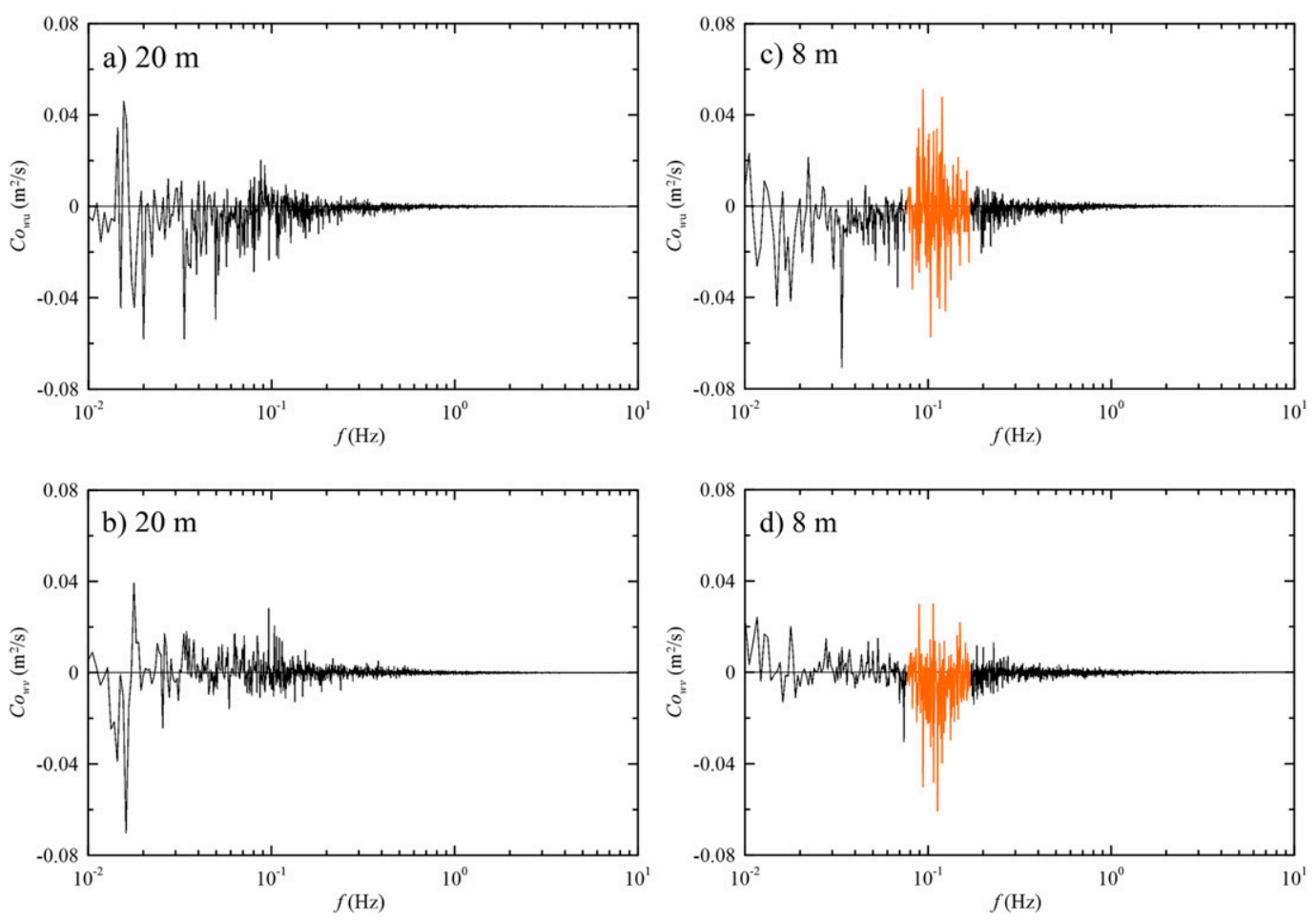

FIG. A1. Wind cospectra as a function of frequency at (a),(b) 20 and (c),(d) $8 \mathrm{~m}$ above the sea surface using the same data as in Fig. 2. The orange area is the swell-related region.

depending on the wavenumber at the wave spectrum peak. Therefore, future studies, especially those based on field experiments, are still required to determine the height of WBL.

Acknowledgments. We thank the professional editors at Textcheck for helping us check the manuscript. This work was supported by the National Natural Science Foundation of China (41830533, 41806028, 41606024, 41976010); the China Postdoctoral Science Foundation (2019 M65206); and the National Basic Research Program of China, Monitoring and Forecasting of Finescale Structure and Impact Assessment of Landfalling Typhoons (2015CB452800).

\section{APPENDIX}

\section{The Method to Derive Turbulent Stress and Swell Wave Coherent Stress from Cospectra}

As described in Zou et al. (2019), the turbulent stress and swell wave coherent stress can be derived from cospectra. If we consider the turbulent stress and swell wave coherent stress both as vectors, the total stress can be calculated by the cospectra between the downwind $u$, crosswind $v$, and vertical $w$ :

$$
\boldsymbol{\tau}=-\int \rho \mathrm{Co}_{w u}(f) d f \mathbf{i}-\int \rho \mathrm{Co}_{w v}(f) d f \mathbf{j},
$$

where $\rho$ is air density; $f$ is frequency; $\mathbf{i}$ and $\mathbf{j}$ represent the longitudinal ( $x$ axis) and lateral ( $y$ axis) unit vector, respectively; and the $x$ axis is aligned with wind direction. The cospectra represent the flux at specific frequencies that contribute to the total stress. A negative $\mathrm{Co}_{u w}$ represents the downward transport of momentum (from air to water) and vice versa. A negative (positive) $\mathrm{Co}_{v w}$ indicates that wind stress is directed to the left (right) on the wind vector.

The swell part of the wave coherent stress has a significant influence on total stress, which can be found in the cospectra (Högström et al. 2015, 2018). Figure A1 shows the wind cospectra as a function of frequency using the same data as in Fig. 2. The along wind cospectra at $20 \mathrm{~m}$ were mostly negative (Fig. A1a), suggesting the downward transport of momentum, while crosswind cospectra (Fig. A1b) were spread randomly over the zero line. However, there was a swell-related region (orange area in Figs. A1c,d) that appeared at the dominant wave frequency.

Figure A1 shows a case when the wind is blowing along swell waves and the turbulent stress turns to the right side of the wind vector (Fig. A2). Here the wind vector was set to point toward the east, the angle 


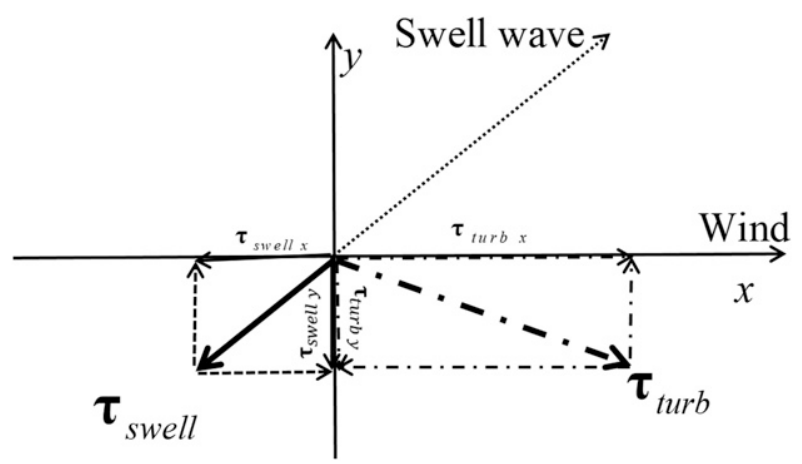

FIG. A2. Schematic of the effect of swell wave coherent stress on turbulent stress for wind following swell case. The turbulent stress turns to the right side of wind vector.

between the turbulent stress and the wind direction was acute and the swell wave coherent stress points to the opposite direction of swell wave. Because the swell waves have a small frequency range and do not interact with the turbulence, the upward momentum transferred from the water surface through Eq. (6) will exert a positive effect in Fig. A1c and a negative effect in Fig. A1d. Thus, Eq. (1) can be divided into two parts:

$$
\begin{aligned}
& \tau_{x}=-\left[\int \rho \mathrm{Co}_{\text {wuturb }}(f) d f+\int \rho \mathrm{Co}_{\text {wuswell }}(f) d f\right], \\
& \tau_{y}=-\left[\int \rho \mathrm{Co}_{\text {wvturb }}(f) d f+\int \rho \mathrm{Co}_{\text {wvswell }}(f) d f\right],
\end{aligned}
$$

where $\mathrm{Co}_{\text {wuswell }}$ corresponds to the orange areas greater than zero in Fig. A1c and $\mathrm{Co}_{\text {wvswell }}$ is the negative orange segment in Fig. A1d. In a similar way, the swell wave coherent stress can be derived by checking the along wind and crosswind cospectra for cases when the wind is blowing against the swell wave or turbulent stress points to the left side of the wind vector.

\section{REFERENCES}

Baas, P., G. J. Steeneveld, B. J. H. Wiel, and A. A. M. Holtslag, 2006: Exploring self-correlation in flux-gradient relationships for stably stratified conditions. J. Atmos. Sci., 63, 3045-3054, https://doi.org/10.1175/JAS3778.1.

Babanin, A. V., J. McConochie, and D. Chalikov, 2018: Winds near the surface of waves: Observations and modeling. J. Phys. Oceanogr., 48, 1079-1088, https://doi.org/10.1175/JPO-D-170009.1.

Buckley, M. P., and F. Veron, 2016: Structure of the airflow above surface waves. J. Phys. Oceanogr., 46, 1377-1397, https:// doi.org/10.1175/JPO-D-15-0135.1.

Drennan, W. M., K. K. Kahma, and M. A. Donelan, 1999: On momentum flux and velocity spectra over waves. Bound.-Layer Meteor., 92, 489-515, https://doi.org/10.1023/A:1002054820455.

Dupuis, H., P. K. Taylor, A. Weill, and K. Katsaros, 1997: Inertial dissipation method applied to derive turbulent fluxes over the ocean during the Surface of the Ocean, Fluxes and Interactions with the Atmosphere/Atlantic Stratocumulus Transition Experiment (SOFIA/ASTEX) and Structure des Echanges Mer-Atmosphere, Proprietes des Heterogeneites Oceaniques: Recherche Experimentale (SEMAPHORE) experiments with low to moderate wind speeds. J. Geophys. Res., 102, 21 115-21 129, https://doi.org/10.1029/97JC00446.

Edson, J. B., and C. W. Fairall, 1998: Similarity relationships in the marine atmospheric surface layer for terms in the TKE and scalar variance budgets. J. Atmos. Sci., 55, 2311-2328, https:// doi.org/10.1175/1520-0469(1998)055<2311:SRITMA >2.0.CO;2.

- — - P. G. Mestayer, and S. E. Larsen, 1991: A study of the inertial-dissipation method for computing air-sea fluxes. J. Geophys. Res., 96, 10 689, https://doi.org/10.1029/91JC00886.

Fairall, C. W., J. B. Edson, S. E. Larsen, and P. G. Mestayer, 1990: Inertial-dissipation air-sea flux measurements: A prototype system using realtime spectral computations. J. Atmos. Oceanic Technol., 7, 425-453, https://doi.org/10.1175/15200426(1990)007<0425:IDASFM>2.0.CO;2.

García-Nava, H., F. J. Ocampo-Torres, P. A. Hwang, and P. Osuna, 2012: Reduction of wind stress due to swell at high wind conditions. J. Geophys. Res., 117, C00J11, https://doi.org/ 10.1029/2011JC007833.

Grachev, A., and C. Fairall, 2001: Upward momentum transfer in the marine boundary layer. J. Phys. Oceanogr., 31, 1698-1711, https:// doi.org/10.1175/1520-0485(2001)031<1698:UMTITM>2.0.CO;2.

Grachev, A. A., C. W. Fairall, J. E. Hare, J. B. Edson, and S. D. Miller, 2003: Wind stress vector over ocean waves. J. Phys. Oceanogr., 33, 2408-2429, https://doi.org/10.1175/1520-0485(2003)033<2408: WSVOOW $>2.0 . \mathrm{CO} ; 2$.

Hackerott, J. A., M. Bakhoday Paskyabi, J. Reuder, A. P. de Oliveira, S. T. Kral, E. P. Marques Filho, M. S. Mesquita, and R. de Camargo, 2017: A surface-layer study of the transport and dissipation of turbulent kinetic energy and the variances of temperature, humidity and $\mathrm{CO}_{2}$. Bound.-Layer Meteor., 165, 211-231, https://doi.org/10.1007/s10546-017-0271-0.

Hanley, K. E., S. E. Belcher, and P. P. Sullivan, 2010: A global climatology of wind-wave interaction. J. Phys. Oceanogr., 40, 1263-1282, https://doi.org/10.1175/2010JPO4377.1.

Hanson, J., and R. Jensen, 2004: Wave system diagnostics for numerical wave models. 8th Int. Workshop on Wave Hindcasting and Forecasting, Oahu, HI, U.S. Army Engineer Research and Development Center's Coastal and Hydraulics Laboratory, Environment Canada, and WMO/IOC Joint Technical Commission for Oceanography and Marine Meteorology (JCOMM), 231-238, http://www.waveworkshop.org/8thWaves/Papers/E3.pdf.

Högström, U., 1988: Non-dimensional wind and temperature profiles in the atmospheric surface layer: A re-evaluation. Bound.-Layer Meteor., 42, 55-78, https://doi.org/10.1007/BF00119875.

, 1990: Analysis of turbulence structure in the surface layer with a modified similarity formulation for near neutral conditions. J. Atmos. Sci., 47, 1949-1972, https://doi.org/10.1175/ 1520-0469(1990)047<1949:AOTSIT>2.0.CO;2.

— , and Coauthors, 2008: Momentum fluxes and wind gradients in the marine boundary layer-A multi platform study. Boreal Environ. Res., 13, 475-502.

— A. Smedman, E. Sahleé, W. M. Drennan, K. K. Kahma, H. Pettersson, and F. Zhang, 2009: The atmospheric boundary layer during swell: A field study and interpretation of the turbulent kinetic energy budget for high wave ages. J. Atmos. Sci., 66, 2764-2779, https://doi.org/10.1175/2009JAS2973.1.

, A. Rutgersson, E. Sahlée, A.-S. Smedman, T. S. Hristov, W. M. Drennan, and K. K. Kahma, 2013: Air-sea interaction 
features in the Baltic Sea and at a Pacific trade-wind site: An inter-comparison study. Bound.-Layer Meteor., 147, 139-163, https://doi.org/10.1007/s10546-012-9776-8.

—, E. Sahlée, A.-S. Smedman, A. Rutgersson, E. Nilsson, K. K. Kahma, and W. M. Drennan, 2015: Surface stress over the ocean in swell-dominated conditions during moderate winds. J. Atmos. Sci., 72, 4777-4795, https://doi.org/10.1175/JAS-D15-0139.1.

,,,,,----- , and,- 2018 : The transition from downward to upward air-sea momentum flux in swelldominated light wind conditions. J. Atmos. Sci., 75, 2579-2588, https://doi.org/10.1175/JAS-D-17-0334.1.

Hristov, T., and J. Ruiz-Plancarte, 2014: Dynamic balances in a wavy boundary layer. J. Phys. Oceanogr., 44, 3185-3194, https://doi.org/10.1175/JPO-D-13-0209.1.

Iwata, T., K. Yoshikawa, Y. Higuchi, T. Yamashita, S. Kato, and E. Ohtaki, 2005: The spectral density technique for the determination of $\mathrm{CO}_{2}$ flux over the ocean. Bound.-Layer Meteor., 117, 511-523, https://doi.org/10.1007/s10546-0052773-4.

Kahma, K. K., M. A. Donelan, W. M. Drennan, and E. A. Terray, 2016: Evidence of energy and momentum flux from swell to wind. J. Phys. Oceanogr., 46, 2143-2156, https://doi.org/ 10.1175/JPO-D-15-0213.1.

Klipp, C. L., and L. Mahrt, 2004: Flux-gradient relationship, selfcorrelation and intermittency in the stable boundary layer. Quart. J. Roy. Meteor. Soc., 130, 2087-2103, https://doi.org/ 10.1256/qj.03.161.

Kundu, P. K., I. M. Cohen, and D. R. Dowling, 2012: Turbulent energy cascade and spectrum. Fluid Mechanics, 5th ed Elsevier Academic Press, 564-571.

Large, W. G., and S. Pond, 1982: Sensible and latent heat flux measurements over the ocean. J. Phys. Oceanogr., 12, 464-482, https:// doi.org/10.1175/1520-0485(1982)012<0464:SALHFM>2.0.CO;2.

Pan, J., D. W. Wang, and P. A. Hwang, 2005: A study of wave effects on wind stress over the ocean in a fetch-limited case. J. Geophys. Res., 110, C02020, https://doi.org/10.1029/ 2003JC002258.

Rieder, K. F., and J. A. Smith, 1998: Removing wave effects from the wind stress vector. J. Geophys. Res., 103, 1363-1374, https://doi.org/10.1029/97JC02571.

Rutgersson, A., E. O. Nilsson, and R. Kumar, 2012: Introducing surface waves in a coupled wave-atmosphere regional climate model: Impact on atmospheric mixing length. J. Geophys. Res., 117, C00J15, https://doi.org/10.1029/2012JC007940.

Sahlée, E., A.-S. Smedman, A. Rutgersson, and U. Högström, 2008: Spectra of $\mathrm{CO}_{2}$ and water vapour in the marine atmospheric surface layer. Bound.-Layer Meteor., 126, 279-295, https://doi.org/10.1007/s10546-007-9230-5.

Semedo, A., K. Sušelj, A. Rutgersson, and A. Sterl, 2011: A global view on the wind sea and swell climate and variability from ERA-40. J. Climate, 24, 1461-1479, https://doi.org/10.1175/ 2010JCLI3718.1.

Sjöblom, A., and A.-S. Smedman, 2002: The turbulent kinetic energy budget in the marine atmospheric surface layer. J. Geophys. Res., 107, 3142, https://doi.org/10.1029/2001JC001016.
- and - 2003: Vertical structure in the marine atmospheric boundary layer and its implication for the inertial dissipation method. Bound.-Layer Meteor., 109, 1-25, https://doi.org/ 10.1023/A:1025407109324.

, and _ 2004: Comparison between eddy-correlation and inertial dissipation methods in the marine atmospheric surface layer. Bound.-Layer Meteor., 110, 141-164, https://doi.org/ 10.1023/A:1026006402060.

Smedman, A., U. Högström, E. Sahleé, W. M. Drennan, K. K. Kahma, H. Pettersson, and F. Zhang, 2009: Observational study of marine atmospheric boundary layer characteristics during swell. J. Atmos. Sci., 66, 2747-2763, https://doi.org/ 10.1175/2009JAS2952.1.

Smith, S. D., and Coauthors, 1992: Sea surface wind stress and drag coefficients: The hexos results. Bound.-Layer Meteor., 60, 109142, https://doi.org/10.1007/BF00122064.

Soloviev, Y. P., and V. N. Kudryavtsev, 2010: Wind-speed undulations over swell: Field experiment and interpretation. Bound.-Layer Meteor., 136, 341-363, https://doi.org/10.1007/ s10546-010-9506-z.

Sørensen, L. L., and S. E. Larsen, 2010: Atmosphere-surface fluxes of $\mathrm{CO}_{2}$ using spectral techniques. Bound.-Layer Meteor., 136, 59-81, https://doi.org/10.1007/s10546-010-9499-7.

Voermans, J. J., H. Rapizo, H. Ma, F. Qiao, and A. V. Babanin, 2019: Air-sea momentum fluxes during Tropical Cyclone Olwyn. J. Phys. Oceanogr., 49, 1369-1379, https://doi.org/ 10.1175/JPO-D-18-0261.1.

Wu, L., A. Rutgersson, E. Sahlée, and X. G. Larsén, 2016: Swell impact on wind stress and atmospheric mixing in a regional coupled atmosphere-wave model. J. Geophys. Res. Oceans, 121, 4633-4648, https://doi.org/10.1002/2015JC011576.

T. Hristov, and A. Rutgersson, 2018: Vertical profiles of wave-coherent momentum flux and velocity variances in the marine atmospheric boundary layer. J. Phys. Oceanogr., 48, 625-641, https://doi.org/10.1175/JPO-D-17-0052.1.

Yelland, M., and P. K. Taylor, 1996: Wind stress measurements from the open ocean. J. Phys. Oceanogr., 26, 541-558, https://doi.org/ 10.1175/1520-0485(1996)026<0541:WSMFTO > 2.0.CO;2.

Zhang, J. A., 2010: Estimation of dissipative heating using lowlevel in situ aircraft observations in the hurricane boundary layer. J. Atmos. Sci., 67, 1853-1862, https://doi.org/10.1175/ 2010JAS3397.1.

Zou, Z., D. Zhao, B. Liu, J. A. Zhang, and J. Huang, 2017: Observation-based parameterization of air-sea fluxes in terms of wind speed and atmospheric stability under low-tomoderate wind conditions. J. Geophys. Res. Oceans, 122, 4123-4142, https://doi.org/10.1002/2016JC012399.

,-- J. A. Zhang, S. Li, Y. Cheng, H. Lv, and X. Ma, 2018: The influence of swell on the atmospheric boundary layer under nonneutral conditions. J. Phys. Oceanogr., 48, 925-936, https://doi.org/10.1175/JPO-D-17-0195.1.

_ , J. Song, P. Li, J. Huang, J. A. Zhang, Z. Wan, and S. Li, 2019: Effects of swell waves on atmospheric boundary layer turbulence: A low wind field study. J. Geophys. Res. Oceans, 124, 5671-5685, https://doi.org/10.1029/2019JC015153. 